\title{
Intumescent paint as fire protection coating
}

\section{Tinta intumescente como revestimento de proteção ao fogo}

R. B. R.S. OLIVEIRA a

rodrigo_brso@yahoo.com.br

A. L. MORENO JUNIOR a almoreno@fec.unicamp.br

L. C. M. VIEIRA a

vieira@fec.unicamp.br

\begin{abstract}
This paper is a compendium on intumescent paint and its main features regarding chemical composition, thermophysical properties and performance as a fire-retardant material. Some of the main technical publications and lines of research on the subject are presented herein. The purpose of this paper is to show the current stage of the technical research being conducted on the topic and enable a better understanding of this fire-retardant material.
\end{abstract}

Keywords: coatings, intumescence, fire-retardant material.

\section{Resumo}

O presente trabalho é um compêndio sobre tintas intumescentes, apresentando as principais características a respeito de sua composição química, propriedades termo físicas e desempenho como material de proteção contra incêndio. São apresentadas algumas das principais publicações técnicas e linhas de pesquisas sobre a intumescência. Objetiva-se, assim, elucidar o atual estágio técnico de pesquisas e possibilitar uma melhor compreensão sobre este material de proteção contra incêndio.

Palavras-chave: tintas, intumescência, materiais de proteção à incêndio.

Faculdade de Engenharia Civil, Arquitetura e Urbanismo da Universidade Estadual de Campinas - UNICAMP, Campinas, SP, Brasil. 


\section{Introduction}

Thermal protection materials are designed to slow the process of combustion heat transfer to the structural element, delaying the effect of temperature variation on its resistance. According to their nature, they can compose an insulating barrier, reducing the heat transfer rate to the protected element. There are also protective materials that develop chemical reactions due to rising temperatures. These reactions can absorb some of the energy that would be aimed at the structural component and/or form material with insulating features.

Heat transfer occurs by physical means via conduction (static means) and convection (moving means). When it does not take place by physical means, heat transfer occurs by radiation, where energy is transferred by electromagnetic waves. A fire protection material can act as a physical barrier, reducing the energy transfer rate. As an example, there are insulating materials such as masonry. Another possibility is the use of a material that, when exposed to high temperatures, undergoes chemical reactions that absorb a significant portion of the energy that would be aimed directly at the structure and/or lead to forming a new thermal protection interface. For example, there is plaster, which due to its ability to maintain and chemically release water, is used as a fire protection material. When heated, the existing chemical bonds in the hydrated plaster begin to break, releasing hydration water. This reaction absorbs energy from the fire that would be conducted to the structural element, thereby forming a thermal barrier. Through this layer, the protected material remains at a constant temperature around $100^{\circ} \mathrm{C}$.

As for intumescent paint, protection materials discussed in this paper, they are chemical compounds which, when subjected to elevated temperatures, undergo various reactions that form a charred foam with high insulation performance.

The advantages of this protection are:

1) They present many of the desirable features of traditional decorative paint as different colors, good surface finish and durability;

2) They do not take up space and load increase is insignificant from a structural point of view;

3) Although they demand experience and strict quality control, their application is simple and does not require attachment to the structure, in addition to easy maintenance properties;

4) They can be used in the protection of structural connecting areas;

5) They do not modify the intrinsic properties of the substrate (as mechanical features). Therefore, they can be applied to existing structures without loss/modification of structural capacity.

In Brazil, the study of structures under fire conditions is relatively recent. The first studies in the area date back to no more than twenty years, for example, Melhado [1], addressing the grounds of the behavior of steel structures under fire conditions and presenting protection criteria. Silva [2] presents the study of the behavior of steel structures exposed to high temperatures. Also are presented expressions and temperature-time curves of the hot gases involving the flames, as well as the influence of ventilation, fire load and cross section geometry when determining the temperature of metallic elements. Safety criteria of the Brazilian and European standards are compared for the status of structures under fire con- ditions and considerations are presented on the simplified design of structural elements.

Among several important studies in the area can be mentioned: Abreu and Fakury [3], with the evaluation of temperature rise in steel profiles, developing a program for determining the temperature of structural elements with and without protection; Fakury [4], whose objective is to promote and illustrate the use of NBR 14323: Design of Steel Structures and Composite Steel and Concrete Structures in Buildings under fire conditions, with calculation methods and aspects regarding steel properties under fire conditions, the combinations of actions, protection of steel structures, temperature rise and critical temperature; Martins [5], with the determination of the critical temperature of bars subjected to normal compression forces and beams without the possibility of buckling laterally or locally and comparison of the resulting resistance when sizing a structure at room temperature and under fire conditions; Lopes Ribeiro [6], assessing the accuracy of regulatory procedures for assessing the distribution of active temperatures in the cross section of structural elements under fire conditions, proposing a computational algorithm for the transient and non-linear thermal analysis of two-dimensional and three-dimensional models.

However, few Brazilian studies are specifically dedicated to the assessment of thermal protection materials for structural elements. With this approach, one can mention Guimarães [7], whose study presents methods available for sizing the coating material of steel structures under fire conditions, and Andrade [8], whose study presents thermal protection materials used in metal buildings and their influence on architectural projects.

Thus, it's noteworthy a lack of Brazilian publications evaluating the nature and performance of specific materials for fire protection. Therefore, the focus and interest of this article is to present the main aspects of intumescent paint as a structural coating, bringing to light the current status of world research on the subject, addressing its chemical composition, performance and thermophysical behavior.

\section{Chemical composition}

In the field of structure engineering, intumescent paint is usually associated as protection material for steel structure under fire conditions, delaying the loss of strength of structural elements. However, intumescent compounds are employed also in the protection of flammable materials and even plastic.

Regardless of their area of use, intumescent compounds basically have the same chemical composition. According to Troitzsch [9], intumescence is obtained by the following components:

- acid source: usually, it is the salt of a non-volatile inorganic acid, such as boric, sulfuric or phosphoric acid. The most used are the salts of phosphoric acid, such as ammonium phosphate and ammonium polyphosphate, which release their acid at temperatures above $150^{\circ} \mathrm{C}$. The resulting acid initiates the first of a series of chemical reactions, beginning with dehydration of carbonaceous compounds and their subsequent charring.

- carbonaceous compound: it is a compound with many hydroxyl radicals $(-\mathrm{OH})$ that dehydrates when subjected to etching through a reaction of esterification and carbonized. Frequently used com- 
pounds are pentaerythritol, amide, and urea-formaldehyde or phenolic resins.

- foaming compounds: for this purpose, compounds such as chlorinated paraffin, melamine or guanidine are used. Under the influence of heat, they release large quantities of non-flammable gases such as hydrogen chloride $(\mathrm{HCl})$, ammonia gas $\left(\mathrm{NH}_{3}\right)$ and carbon dioxide $\left(\mathrm{CO}_{2}\right)$, generating a foam with an aspect of carbonized material on the substrate. Decomposition products of these materials (e.g., chlorinated paraffin residues) often contribute to further carbonization of the carbonaceous compound.

- binding resins: responsible for involving the gases, preventing their dispersal. They must not harden. Instead, for better performance, they must have thermoplastic characteristics. An example of highly recommended materials are chlorine-based rubbers, which soften and melt when exposed to high temperatures and, simultaneously, aid the expansive agent forming $\mathrm{HCl}$, besides contributing to carbonization.

Camino et al [10] cites a 1948 American patent record to present chemical composition of an intumescent compound. According to the record, in the formulation of intumescence, the carbonaceous compound is the source of carbon to form carbonized foaming that involves the gases. Vandersall apud Camino et al [10] classified the chemical components of the intumescent systems into four categories:
1. Inorganic acid, free or originated due to the rise in temperature to $100-250^{\circ} \mathrm{C}$;

2. Polyhydric compound rich in carbon;

3. Organic amine or amide;

4. Halogen compound (usually formed by fluorine or chlorine). Some of the components shown in Table 1 act in more than one of the above groups and thus perform more than a single function in intumescence. However, the combination of any four elements that meet the conditions listed above is no guarantee that the intumescent behavior will be developed by the mixture.

For intumescence to develop, a series of chemical and physical processes must occur in the proper sequence, as the temperature is raised. The carbonaceous compound should not decompose or volatilize before the acid is available to dehydrate it. Also, gases responsible for foaming must be developed through small bubbles dispersed in the carbonized mass, resulting in an aerated compound. This process requires a suitable gas development rate and viscosity of the formed mass. The viscosity of any fluid comes from its internal friction, which originates from the attractive forces between relatively close molecules. Thus, the smaller the intermolecular forces, the lower the viscosity. If the formed mass has low viscosity, the gases will escape, resulting in a poor foam whose surface is filled with breaks. However, if the viscosity is too high, the intumescence does not develop.

\section{Table 1}

Examples of materials that meet the formulation of intumescence

(Source: Vandersall apud Camino et al (10))

\begin{tabular}{|c|}
\hline 1. Source of inorganic acids \\
\hline A. Acids \\
\hline Phosphoric \\
\hline Sulfuric \\
\hline Boric \\
\hline
\end{tabular}

\begin{tabular}{|c|}
\hline B. Ammonium salts \\
\hline Phosphates, polyphosphates \\
\hline Sulphates \\
\hline Halides \\
\hline
\end{tabular}

\begin{tabular}{|c|}
\hline C. Phosphates amine / amide \\
\hline Urea \\
\hline Product of ammonium and phosphate reaction \\
\hline Melamine \\
\hline
\end{tabular}

\begin{tabular}{|c|}
\hline D. Phosphorus organic compounds \\
\hline Tricresyl phosphate \\
\hline Alkyl phosphates \\
\hline Haloalkyl phosphates \\
\hline
\end{tabular}

\begin{tabular}{|c|}
\hline 2. Polyhydric compounds \\
\hline Amide \\
\hline Dextrin \\
\hline Sorbitol \\
\hline Pentaerythritol \\
\hline Phenol-formaldehyde resins \\
\hline Methylol melamine \\
\hline 3. Amines/amides \\
\hline Urea \\
\hline Urea-formaldehyde resins \\
\hline Polyamides \\
\hline
\end{tabular}

\begin{tabular}{|c|}
\hline 4. Halogenated compounds \\
\hline Chlorinated paraffins \\
\hline Tetrachloro phthalic resins \\
\hline
\end{tabular}


In general, carbonized foam has gas bubbles with diameters between 20 and 50 micrometers and wall thickness from 6 to $8 \mathrm{mi}-$ crometers. Sometimes inert fine aggregates are added, such as titanium dioxide and silica, to allow greater control over the size of the bubbles formed. Other elements are added to intumescent compounds to increase their mechanical and thermal performance. For example, the addition of vitrification agents, such as borates and mineral fibers, increases resistance to physical impact from air currents during fire.

Despite the high amount of materials shown in Table 1 for the formulation of intumescent compounds, only a few are used in practice and, in general, they were empirically chosen. The compounds usually employed, as cited by Camino et al [10] coincide with those presented by Troitzsch [9]. For inorganic acid, with a high boiling point and reduced oxidation, typically phosphoric acid is used, in the form of ammonium salts. For protective coatings, ammonium polyphosphates are the most widely used as they are poorly soluble in water, interesting feature for a material that, depending on the application, may be exposed to weathering. Pentaerythritol and their oligomers are the traditional polyhydric compounds. Chlorinated paraffin is the most widely used halogen compound. However, there is a tendency to avoid the use of halogens in the formulation of intumescent materials due to its dark and potentially toxic and corrosive fumes. Camino et al [10] also suggests the hypothesis that the role of these compounds in intumescence, forming gases which will inflate the carbonized foam, is mainly performed by other gases originated from other components of the intumescent system.

\section{Chemical reactions of intumescent systems}

As previously mentioned, in intumescent systems, in general, carbonization occurs by the interaction between the inorganic acid and a polyhydric compound. Cellulose is the polyhydric compound whose carbonization reaction by inorganic acids have been most studied, since it is the most abundant naturally available organic material and also for being a major fuel source for fire. These studies provided information on the acidic dehydration mechanism, which can be assumed to be comparable to other polyhydric compounds with similar structure to cellulose. However, the structure of Pentaerythritol is quite different from cellulose and thus, one can't correlate the carbonization processes.

Vandersall apud Camino et al [10] reports that, with a gradual increase in temperature, dipentaerythritol - ammonium polyphosphates - soften and melt at $215^{\circ} \mathrm{C}$, staying with clear aspect to $238^{\circ} \mathrm{C}$, when gas development starts. Then the mass darkens and hardens at $360^{\circ} \mathrm{C}$. Therefore, the following sequence is suggested: 1. Phosphate breakdown at $215^{\circ} \mathrm{C}$;

2. Subsequent esterification of alcohol, forming water;

3. Solidification of phosphorus-carbon carbonized foam at $360^{\circ} \mathrm{C}$. Next, the chemical reactions according to Troitzsch [9] are presented, for the intumescent mechanism of ammonium dihydrogen phosphate, Pentaerythritol and chlorinated paraffin. The first step takes place at temperatures between 150 and $215^{\circ} \mathrm{C}$ - decomposition of the inorganic salt producing ammonia gas and phosphoric acid, according to Equation 1.

$$
\mathrm{NH}_{4} \mathrm{H}_{2} \mathrm{PO}_{4} \stackrel{\mathrm{n}}{\rightarrow} \mathrm{NH}_{3}+\mathrm{H}_{3} \mathrm{PO}_{4}
$$

At a slightly higher temperature, the acid formed reacts with the carbonaceous compound, esterifying the polyhydric compound. This reaction is shown in Equation 2 and may be catalyzed by amines and amides.

$$
\mathrm{C}_{5} \mathrm{H}_{8}(\mathrm{OH})_{4}+\mathrm{H}_{3} \mathrm{PO}_{4} \rightarrow \mathrm{C}_{5} \mathrm{H}_{8}(\mathrm{OH})_{4} \cdot \mathrm{H}_{3} \mathrm{PO}_{4}
$$

With temperatures ranging from those presented in the first step and during esterification, the binder partially melts.

Between 280 and $350^{\circ} \mathrm{C}$ phosphoric ester breaks down, according to Equation 3 - the mixture melts and bonds are broken, forming acid, water and carbon residue.

$$
\mathrm{C}_{5} \mathrm{H}_{8}(\mathrm{OH})_{4} \cdot \mathrm{H}_{3} \mathrm{PO}_{4} \stackrel{\mathrm{n}}{\rightarrow} \mathrm{H}_{3} \mathrm{PO}_{4}+\mathrm{H}_{2} \mathrm{O}+\mathrm{C}
$$

At the same time the reaction occurs in Equation 4, where the compound responsible for providing gases that will inflate the mixture decomposes, releasing gases (such as hydrogen chloride or hydrochloric acid) inflating the melted mass.

$\mathrm{C}_{\mathrm{n}} \mathrm{H}_{(2 \mathrm{n}+1)} \mathrm{Cl} \rightarrow \mathrm{HCl}+\mathrm{C}$

The binder resin, softened, forms a thin layer on the mixture, preventing the gases from dissipating. As temperature is elevated, the viscosity of the foam increases. Because of crosslinking and carbonization, the formed foam solidifies, forming a highly porous material. At temperatures above $600^{\circ} \mathrm{C}$ occurs thermal decomposition and/or oxidation of the carbonized mass.

When compared to the original thickness, the intumescent layer is about 50 to 100 times larger, forming a thermal barrier that protects the substrate from heat influence and decomposing.

\section{Intumescent paint}

In general, there are two types of coatings that play a role in fire protection: flame retardants and intumescent paint. Flame retardant paint helps to control the spread of the fire to a small region or even reduce its spread. However, this type of paint does not provide protection against fire to the substrate where it is applied. It is usually intended for protection of structures or components of ships and boats.

As for intumescent paint, it is generally used for protection of wood and steel structures, as well as fabrics and plastic substrates. To its chemical composition, described above, dyes are added and/or other components to increase its mechanical and chemical resistance. One aspect to be evaluated in intumescent paint is its relative solubility in water. If used on surfaces susceptible to contact with water or moist environments, the performance of substrate protection is reduced due to possible leaching of the compounds responsible for intumescence. One solution is the adoption of a waterproof coating over the intumescent paint. According to Troitzsch [9], formulations with ammonium polyphosphate or melamine phosphate perform better regarding water resistance.

Sometimes, the intumescent coating is reinforced with epoxy resins with mixtures of boric acid or borates, glass and lime. During combustion, the epoxy resin is attached to the hydroxyl radicals 
contained in the glass; this results in an inflated foam with high mechanical strength.

In metallic structures, the interaction of intumescent paint with underlying primer is also very important, although few publications are aimed at the subject. Primer ensures good adhesion between the metal substrate and the paint, and provides increased corrosion resistance. Ullah et al apud Norgaard et al [11] conducted studies with metal profiles with zinc-based primer, protected by intumescent paint comprised of expandable graphite, ammonium polyphosphate, melamine, boric acid, bisphenol-A epoxy resin and solidifying polyimide. The effects of varying the chemical formulation of the paint in the steel-primer-paint system were analyzed by a scanning electron microscopy before and after heating the assembly in an oven at $500^{\circ} \mathrm{C}$. The studies have shown that the composition of best performance had weight percentages of $25 \%$ ammonium polyphosphate and $15 \%$ boric acid. According to the European guideline for testing intumescent paint - ETAG 018 - the importance of primer is emphasized: when an intumescent paint is approved, which primers can be employed with the coating must be specified. Additionally, correlations are proposed between the tests conducted in the primer-intumescent system, primer's thickness and the presence of gas (oxygen) during intumescence. The reason for this assessment is that oxygen concentration near the primer, whose performance is related to the thickness of the film to which it was applied, may vary due to carbonized foam formed by the intumescent paint.

The expected performance for a metallic component exposed to fire is to be able to remain structurally functional for a certain period of time. According to the US standard AISC (American Institute of Steel Construction) - Design Guide 19, it is possible to reasonably predict the temperature limit at which will occur the structural collapse. According to test results, while no cross section along the metallic element has temperatures above $1000^{\circ} \mathrm{F}\left(538^{\circ} \mathrm{C}\right)$, it can be observed that this section remains capable of being subjected to external loadings. Also according to tests, another temperature limit was observed: $1200^{\circ} \mathrm{F}\left(649^{\circ} \mathrm{C}\right)$ anywhere on the bar - when there is a $50 \%$ loss of strength. It is assumed, therefore, that these temperatures are limits for heat transfer analysis and represent a load capacity criterion for testing with protective material in metallic structures. The standard ASTM (American Society for Testing and Materials) $\mathrm{E}-119$ regulates the procedures for tests with loadings. For this type of assessment, the maximum design load or a percentage (payload) is used. Therefore, protection is assessed as acceptable if the column supports the loading imposed during a regulated period, and temperature is elevated according to standardized rates.

It is common to distinguish between intumescent paint for the protection of elements subjected to hydrocarbon and cellulosic fire. For each fire situation, the temperature rise rate changes. Conventionally, standard fire is adopted as a model of fire designed for experimental analyzes of structures or protection materials, where it is assumed that gas temperature in the compartment complies with standard curves. These standard curves show as similarity only the ascending branch, with temperature increasing over time, regardless of the influence of the fire load, the degree of ventilation and thermal properties of partitioning materials. The best known curves describe the fire whose combustible material is comprised of cellulosic materials. Hydrocarbon curves have a temperature rise rate higher than cellulosic.

The performance of intumescent paint is evaluated based on numerous and costly standardized tests. A study aiming to predict the performance of coatings subjected to hydrocarbon fire was conducted by Jimenez et al [12], correlating the results of tests performed in laboratory with the results of standard tests. It was verified that a key parameter was the mechanical compressive strength of the intumescent compound after being exposed to $500^{\circ} \mathrm{C}$ at a temperature elevation rate of $10^{\circ} \mathrm{C} / \mathrm{min}$. In Reshetnikov et al [13] several methods for measuring the mechanical strength of intumescent paint are described. One of the proposed methods is to obtain the minimum strength necessary to destroy the intumescent compound, inserting a rod through the sample heated to temperatures exceeding $1200^{\circ} \mathrm{C}$.

In special cases that may come up during a fire, coatings for cellulosic fires may be exposed to higher rates of temperature rise. For example, if the intumescent compound is found at elevated temperatures and is damaged by objects detached from the building or even projected towards the coated element, as a result of fire. The residual underlying layer, not yet inflated, is instantaneously exposed to a much higher temperature rise rate. Tests carried out by Noorgard et al [14], assessed the performance of the strength of the intumescent compound and expansion properties (degree of expansion and loss of mass) of intumescent paint for cellulosic fire subjected to elevated temperature rise rates. Initially, it was expected that the energy required to break the intumescent paint would be greater for thinner samples, which was not confirmed in the tests.

\section{Thermophysical properties of intumescent paint}

In the literature, there are different models to treat intumescence behavior as a problem of heat transfer. There are models that describe intumescence and the formation of carbonaceous foam based on thermal degradation kinetic modeling, considering chemical reactions that have occurred, transportation and thermal phenomena. Given the complexity of thermal decomposition of the compounds responsible for intumescence, the existing models are based on certain simplifications, such as consideration of a onedimensional model of heat transfer, thermal properties independent of temperature and space, and the incidence of constant heat flux, where heat losses by radiation and convection are ignored. In general, it is also considered that the intumescence thermochemical processes occur without release or absorption of heat.

In a study developed for NASA - National Aeronautics and Space Administration - Clark et al [15] proposed an analytical model for intumescent paint focused on the protection of metal storage tanks for kerosene-based fuels. The chemical research division of NASA was one of the pioneers in the development of intumescent paint and rigid and semi-rigid foams used as thermal protection systems. During the study two ways were considered for use of the intumescent paint assessed: direct application or over an intermediate inert insulating layer bonded to the metal substrate. The objective of this study was to develop analytical mechanisms for studying and predicting the paint thermodynamic response when exposed 
to fire conditions, thus obtaining the combination of paint and insulation (if used) thicknesses that would result in better thermal protection performance. The analysis was performed in three steps, as shown in Figure 1:

1. Set thermal conditions:
a. Paint temperature, pressure and chemical composition;
b. Heat and mass transfer coefficient;
c. Heat flow by radiation;

2. Calculate a solution matrix for the volume control surface conditions that satisfy, simultaneously, mass balance and chemical equilibrium constraints;

3. Determine the material mass and energy balance equations using the solutions obtained above and the energy balance of the volume control surface.

Adopting the same symbology, Clark et al [15] proposes that the first stage of the analysis is based on mass balance. Thus, a link can be established between mass flow by total diffusion $\left(\mathrm{j}_{\mathrm{k}_{\mathrm{w}}}\right)$, normal density and convective speed for the paint control surface $((\rho . v) w)$ and the total mass fraction of the paint surface $\left(\mathrm{k}_{\mathrm{k}_{\mathrm{w}}}\right)$, with mass flow rates of carbonized $\left(\mathrm{m}_{\mathrm{c}}\right)$ and pyrolysis gases $\left(\mathrm{m}_{\mathrm{g}}\right)$ and mass fraction burnt $\left(\mathrm{k}_{\mathrm{k}_{\mathrm{c}}}\right)$ and gases released into intumescence ( $\mathrm{k}_{\mathrm{kg}_{\mathrm{g}}}$ ), according to the equation below.

$$
\mathrm{j}_{\mathrm{k}_{\mathrm{w}}}+(\rho \cdot \mathrm{v})_{\mathrm{w}} \cdot \mathrm{k}_{\mathrm{k}_{\mathrm{w}}}=\mathrm{m}_{\mathrm{g}} \cdot \mathrm{k}_{\mathrm{k}_{\mathrm{g}}}+\mathrm{m}_{\mathrm{c}} \cdot \mathrm{k}_{\mathrm{k}_{\mathrm{c}}}
$$

The mass flow rate by diffusion through the paint surface is explained by paint density $\left(\rho_{\mathrm{e}}\right)$, gas speed across its surface $\left(\mathrm{u}_{\mathrm{e}}\right)$, Stanton number for mass transfer $\left(\mathrm{C}_{\mathrm{M}}\right)$ and the difference between the mass fraction on the surface $\left(\mathrm{k}_{\mathrm{k}_{\mathrm{w}}}\right)$ and external to the paint $\left(\mathrm{k}_{\mathrm{k}_{\mathrm{e}}}\right)$.

$\mathrm{j}_{\mathrm{k}_{\mathrm{w}}}=\rho_{\mathrm{e}} \cdot \mathrm{u}_{\mathrm{e}} \cdot \mathrm{c}_{\mathrm{M}}\left(\mathrm{k}_{\mathrm{k}_{\mathrm{w}}}-\mathrm{k}_{\mathrm{k}_{\mathrm{e}}}\right)$

Combining the two equations above and normalizing them with the mass transfer coefficient, the result is:

$\left(\mathrm{k}_{\mathrm{k}_{\mathrm{w}}}-\mathrm{k}_{\mathrm{k}_{\mathrm{e}}}\right)+\frac{(\rho \cdot \mathrm{v})_{\mathrm{w}}}{\rho_{\mathrm{e}} \cdot \mathrm{u}_{\mathrm{e}} \cdot \mathrm{c}_{\mathrm{M}}} \cdot \mathrm{k}_{\mathrm{k}_{\mathrm{w}}}=\mathrm{B}_{\mathrm{g}}^{\prime} \cdot \mathrm{k}_{\mathrm{k}_{\mathrm{g}}}+\mathrm{B}_{\mathrm{c}}^{\prime} \cdot \mathrm{k}_{\mathrm{k}_{\mathrm{c}}}$

Where:

$B_{g}^{\prime}=\frac{m_{g}}{\rho_{e} \cdot u_{e} \cdot c_{M}} ; B_{c}^{\prime}=\frac{m_{c}}{\rho_{e} \cdot u_{e} \cdot c_{M}}$

The surface mass balance is obtained by the system:

$(\rho . \mathrm{v})_{\mathrm{w}}=\mathrm{m}_{\mathrm{g}} \cdot+\mathrm{m}_{\mathrm{c}}$

That can be linearized to obtain:

$\mathrm{B}^{\prime}=\frac{(\rho \cdot \mathrm{v})_{\mathrm{w}}}{\rho_{\mathrm{e}} \cdot \mathrm{u}_{\mathrm{e}} \cdot \mathrm{c}_{\mathrm{M}}}=\mathrm{B}_{\mathrm{g}}^{\prime}+\mathrm{B}_{\mathrm{c}}^{\prime}$

According to Clark et al [15] the first step of the calculation process - setting thermal conditions - provides the mass fraction on the

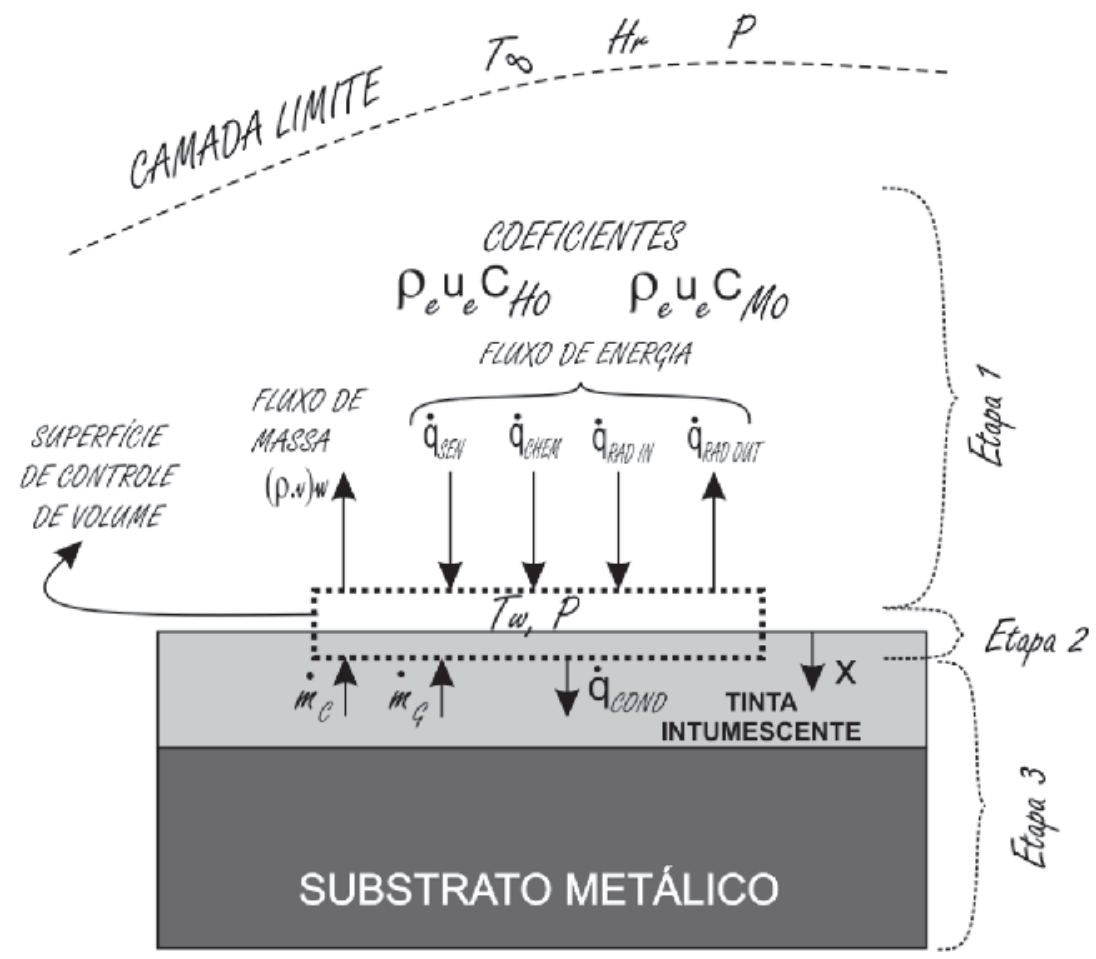

\section{Figure 1}

Scheme of the procedure adopted to predict the electrochemical behavior of coating (Source: Adapted of Clark et al (15)) 
external surface of the paint, $\left(\mathrm{k}_{\mathrm{k}_{\mathrm{e}}}\right)$, and the static pressure. If $\mathrm{B}_{\mathrm{g}}$ and $\mathrm{B}_{\mathrm{c}}$ are specified and thermochemical data from all possible compositions are available, the above equations can be solved, in conjunction with balance equations of the law of mass action, allowing to obtain the mass fraction $\left(\mathrm{k}_{\mathrm{k}_{\mathrm{w}}}\right)$ and all thermodynamic properties of the mixture for the gas adjacent to the surface. With this done for a range of values $\mathrm{B}_{\mathrm{g}}^{\prime}$ and $\mathrm{B}_{\mathrm{c}}^{\prime}$, the second step is complete. The result is a solution matrix for surface conditions, which will be used in the last step of the calculation.

Thermodynamic characteristics intrinsic of intumescent paint were assumed by the average of the properties for pure and totally carbonized matter. Models of intumescent paint with different thicknesses were assessed, in addition to models with intermediate inert insulating layer of variable thickness. Performance of the relation intumescent paint and insulation layer is given in terms of the time required for the metal substrate to reach a certain temperature, so that this relation is considered as optimum for the longest period obtained.

Assessing the results shown by Clark et al [15] it is possible to notice that by exposing a 1.52 millimeter steel plate without any thermal protection to a heat flux of $17.03 \mathrm{~W} / \mathrm{cm}^{2}\left(15 \mathrm{Btu} / \mathrm{ft}^{2} . \mathrm{sec}\right)$, the
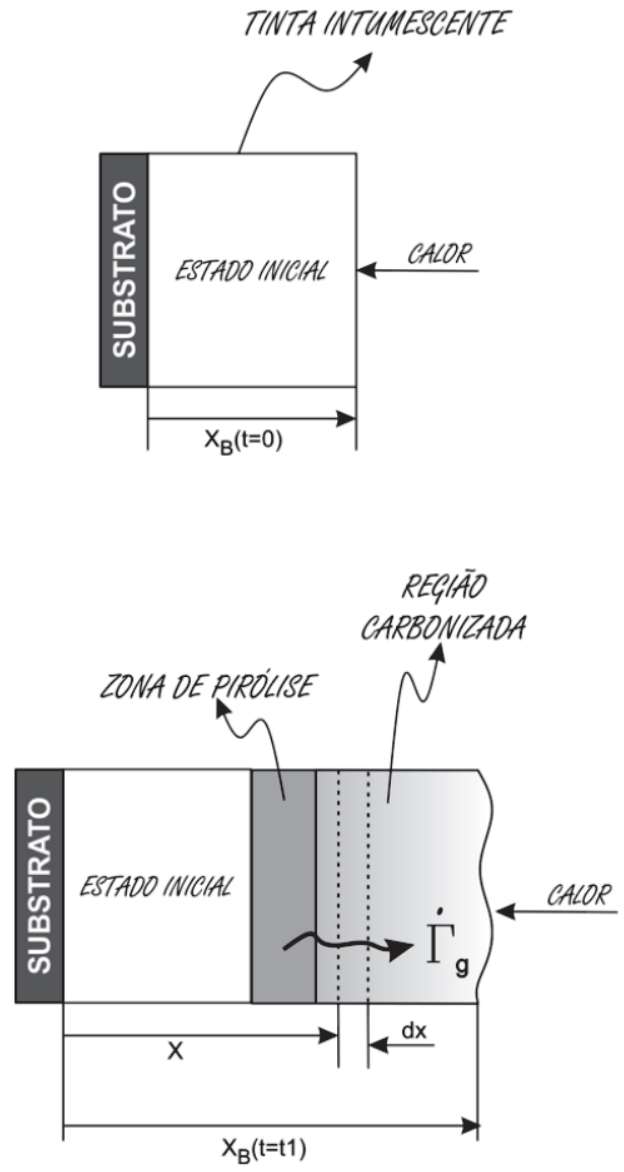

\section{Figure 2}

Representation of the one-directional model (Source: Adapted of Anderson et al (16)) temperature on the opposite side to the incidence of heat will reach $1250^{\circ} \mathrm{C}$ in 30 seconds. For the same conditions, applying a layer of $1.02 \mathrm{~mm}$ from the assessed intumescent paint, this time increases to two minutes. There were no major conclusions regarding the determination of the best ratio between the thicknesses of insulator and paint, since it varies depending on heat flux and temperature limit of the metal substrate. However, as expected, it is evident that the use of an intermediate inert insulating layer further increases the performance of thermal protection.

Anderson et al [16] also proposes a mathematical model to describe the several physical processes of an intumescent system considering mass and energy control. The process of expansion during intumescence is depicted based on loss of mass. Experimental data were obtained by thermogravimetric analysis - measuring the loss in mass according to the evolution of the temperature - and differential scanning calorimetry - assessing the energy needed to maintain the thermal equilibrium of the sample analyzed in relation to a given reference. Chemical composition of the paint used in the tests was proposed by the US Navy, whose interest in intumescent paint was drawn after two major fires that occurred in aircraft carriers (USS Forrestal in July 1967 and USS Enterprise in January 1969) victimizing about 150 people and with a total loss of more than US $\$ 130$ million. It was proposed the one-dimensional thermodynamic model presented in figure [2]. At time $t=0$, the paint is in its pure composition, initial. At time $\mathrm{t} 1$, heat leads to intumescence the system, which is expanded and partly carbonized. Eventually, as heat is applied for enough time, all paint will be carbonized. Again, maintaining the nomenclature used by Anderson et al [16], by applying conservation of mass and energy to the differential volume control, results in the equations below.

$\frac{\mathrm{d} \rho}{\mathrm{dt}}+\rho \frac{\delta \mathrm{v}}{\delta \mathrm{x}}=-\Gamma_{\mathrm{g}}$

$\rho \cdot \mathrm{C}_{\mathrm{p}} \frac{\mathrm{dT}}{\mathrm{dt}}=\frac{\delta}{\delta \mathrm{x}} \mathrm{k} \frac{\delta \mathrm{T}}{\delta \mathrm{x}}-\left(\mathrm{h}_{\mathrm{g}}-\mathrm{h}\right)$.

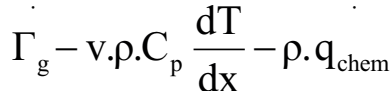

Density of the material is expressed by $\rho$. As the paint expands by intumescence, total mass decreases due to formation/release of gases $\left(\Gamma_{\mathrm{g}}\right)$. These gases trapped in the melted material, are responsible for the expansion of the material that occurs with velocity v. In Equation 12, $\mathrm{T}$ is the temperature, $\mathrm{k}$ is the thermal conductivity, $C_{p}$ is the specific heat, $h$ and $h_{g}$ are the specific enthalpies of the solid and gas, and $\mathrm{q}_{\text {chem }}$ is the heat rate per mass unit generated by the chemical reactions. Analogously to Clark et al [15], it is proposed the relationship between mass loss (where the original mass $\mathrm{m}_{0}$ is the final mass $\mathrm{m}_{\mathrm{c}}$ - or carbonized - and is the mass at the assessed instant $\mathrm{m}$ ) and expansion (expressed by current expansion factor $\mathrm{E}_{\mathrm{f}}$ relative to the maximum $\left(\left(\mathrm{E}_{\mathrm{f}}\right)_{\text {máx }}\right)$ in equation 13.

$\mathrm{E}_{\mathrm{f}}=1+\left[\left(\mathrm{E}_{\mathrm{f}}\right)_{\max }-1\right] \cdot\left[\frac{\mathrm{m}_{0}-\mathrm{m}}{\mathrm{m}_{0}-\mathrm{m}_{\mathrm{c}}}\right]^{\mathrm{n}}$

The exponent $\mathrm{n}$ of the above equation describes the dependence 
of the expansion factor with the initial mass change. If the expansion starts quickly during the gas release stage, which means that small changes in initial mass result in significant expansion, the value of exponent $n$ is between 0 and 1 - the expansion rate is close to the maximum rate. If expansion occurs after most of the gas release stage has elapsed, the factor is greater than 1 . If $n$ is equal to 1 , there is a direct relation between the production of gas and expansion.

Anderson et al [16] also proposes that the velocity $v$ of a particle can be expressed by differentiating the expression that shows the movement of the particle, in terms of its initial coordinate. Equation 14 , wherein $y$ is the expansion coordinate (or intumescence) of the moving particle, shows that the velocity at a location $x$ depends on the cumulative effect of what occurs inside the point.

$\mathrm{v}(\mathrm{x}, \mathrm{t})=\frac{\mathrm{dy}}{\mathrm{dt}}=\int_{0}^{\mathrm{x}} \frac{-\mathrm{n}}{\mathrm{m}_{0}-\mathrm{m}}\left[\mathrm{E}_{\mathrm{f}}(\mathrm{m})-1\right] \frac{\mathrm{dm}}{\mathrm{dt}} \mathrm{dt}$

The boundary condition external to the system is that heat flow is continuous at $x=x_{\beta}$, from which the surface temperature can be determined. The boundary condition at the interface of paint with the substrate is also that heat flow is continuous. However, due to the high value of thermal conductivity of the substrate under consideration (steel) and assumed small thickness of the order of 1 to 2 millimeters, it is assumed that there is no temperature gradient through the substrate thickness. This condition allows to determine the temperature of the substrate, which is also the temperature at the interface with the paint.

Thus, the analytical model proposed by Anderson et al [16] for intumescent paint includes mass change and expansion of the paint by relating them to the temperature rise of the metal substrate. For numerical solution of the differential equations proposed, the paint was divided into increments (zones). Being the model onedimensional, each increment can be approximated to a point, simplifying the overall solution. Evaluating the results, it is possible to note that, despite the simplifications, the model is quite reasonable and the substrate temperature-time relation varies depending on the heat flux applied to the surface of the paint, its chemical composition and the physical characteristics developed during the intumescence process.

According to the one-dimensional model proposed by Buckmaster et al [17] apud Deogon et al [18], when heat is applied to a surface protected with intumescent paint, it is assumed that no reactions occur until the critical temperature is reached. Subsequently, an infinitesimal layer, on which intumescence develops, moves along the thickness of the paint. The temperature in this thin layer remains constantly equal to the critical temperature. In the region where this layer has passed, temperature is greater than critical and the remaining portion presents temperature lower than critical. The behavior of the intumescent paint, when exposed to high temperature, can be divided into three stages:

1. The temperature of the outer surface of the paint is elevated from the initial temperature to the critical temperature. The thermal parameters involved in this phase are characteristic of intumescent paint.

2. The infinitesimal layer with constant temperature equal to critical, moves along the thickness of the paint to the substrate. Thus, this stage ends when the layer reaches the substrate. The thermal parameters of this period are dependent on the thermal characteristics of the paint and the carbonized foam developed, with a jump of these properties in the infinitesimal layer.

3. Thermal parameters are continuous, but now depicting the features of intumescent foam.

Buckmaster et al [17] differs from previous studies by the way intumescence is addressed. According to the author, heating the paint in a controlled manner in an oven, it is possible to note a significant loss of mass only from a particular (and relatively high) temperature. Until this temperature is reached, the mass remains relatively constant. Thus, since the previous models propose direct correlation with mass loss, intumescence would occur only from a considerable temperature range. As shown above, the proposed model assumes that intumescence develops throughout the paint layer. As an advantage, in addition to consistent results with experimental data, it eliminates adopting the most difficult part to characterize the problem - the intumescence process. Another important conclusion of this study is that intumescence is an endothermic process, in other words, it absorbs system energy. Although, in general, this feature is neglected, protection provided by intumescent paint increases considerably.

Staggs [19] proposes to estimate, through numerical simulations, the thermal conductivity of intumescent paint. His study aims to use highly segmented images, monochromatic, from an intumescent section to build a finite element model. The fact that a flat image is used to estimate inherently three-dimensional features requires the adoption of assumptions regarding the $3 \mathrm{D}$ structure. For example, it is assumed that the porosity in the flat image, defined as the ratio of the empty area by the total area, is equal to the spatial porosity.

The proposed finite element model consists of square elements, where an element corresponds to a pixel of the digital image. The image, originally in gray scale, is segmented in black and white. Each pixel is classified as solid or empty, according to their color (black are solid and white are empty). Thus, the intumescent macrostructure is portrayed very realistically. For each element, a thermal conductivity is assigned, according to the colors. Pixels corresponding to empty receive thermal conductivity from the air. Tests using the hot plate method were used to estimate thermal conductivity of the solid elements (intumescent portion). However, thermal conductivity of an element that is not empty is more complex. It is noted that macro porosity corresponds to only one third of the total porosity. Thus, micro porosity should be included in the thermal conductivity assessment. A sub-model was used to determine thermal conductivity of non-empty elements, by analysis using a transmission electron microscope.

As thermal conductivity of each element is assigned, it is possible to calculate the overall thermal conductivity of the two-dimensional model. Imposing constant temperature boundary conditions at the top and bottom of the paint layer and adiabatic conditions in the other layers, the temperature is calculated inside the domain and the heat flow of the element mesh. Figure [3] compares the results of the numerical method proposed by Staggs [19] with three samples of intumescent paint tested through the hot plate method to estimate thermal conductivity.

Some aspects should be observed on the proposed model above. 


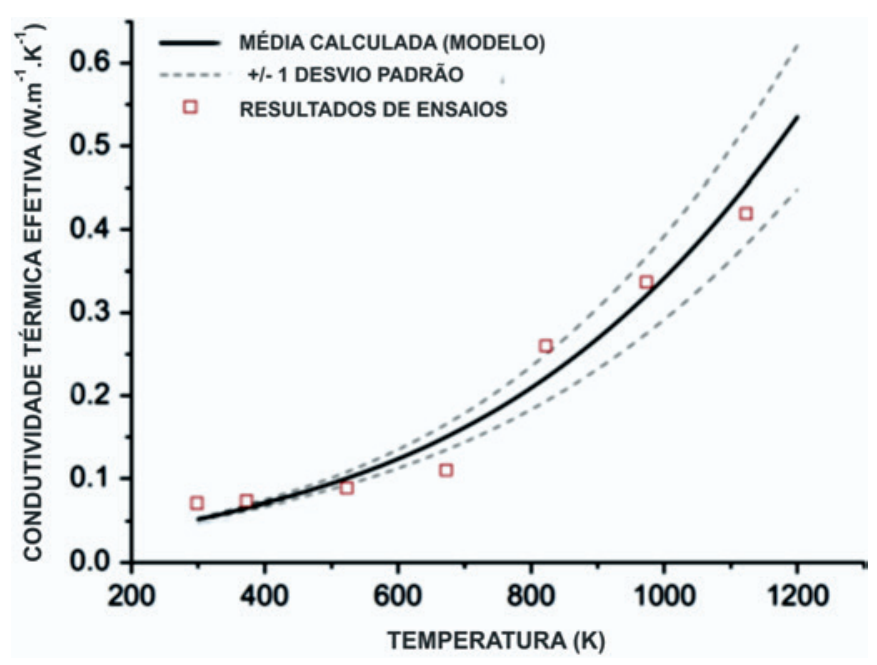

Figure 3

Comparison of thermal conductivity between the numerical method, and laboratory tests

(Source: Adpated of Staggs (19))

The first relates to the dependence of thermal conductivity with temperature. Staggs [19] elucidates that under high temperatures, radiation through the pores significantly increases the apparent thermal conductivity. For this matter, numerical approximations are proposed based on pore size, depicting additional heat flow by radiation. Another aspect relates to the progress of effective thermal conductivity throughout the development of intumescence. The results presented depict, with considerable accuracy, the behavior of a completely intumesced section, regardless of their relation with the thermal properties developed during the chemical process.

According to Mesquita et al [20] determining the intumescent material temperatures involves a stage transformation with two or more moving boundaries: initial composition, pasty layer and carbonized layer. It is also stated that the performance of the intumescent protection is directly related to the temperature or time that intumescence starts and the period during which it acts as a thermal barrier. The proposed model analyzes the development of intumescence as a one-dimensional problem, where the heat flux propagates through the paint. It is assumed that the transition from initial state to carbonized occurs in a very thin layer, enabled at a critical temperature. After the heating stage, the surface reaches the transition temperature and protection can be divided into two layers. However, aiming to determine an estimated value of thermal conductivity of the intumescent portion, it is assumed that this is constituted by a single layer of specific mass and constant specific heat.

The boundary condition on the outer surface of the paint determines that the heat flow passing through the intumescent layer is equal to the heat flow from the fire (or the assessed test), except for the heat losses by convection and radiation. As Anderson et al [16], it is considered that there is no temperature gradient in the metal plate assessed, due to low thickness and high diffusivity. Also, it is assumed that the substrate base has adiabatic characteristics, with no heat exchange with the external environment.

Figure [4] shows the numerical result of the effective thermal conductivity, assuming the same experimental test conditions

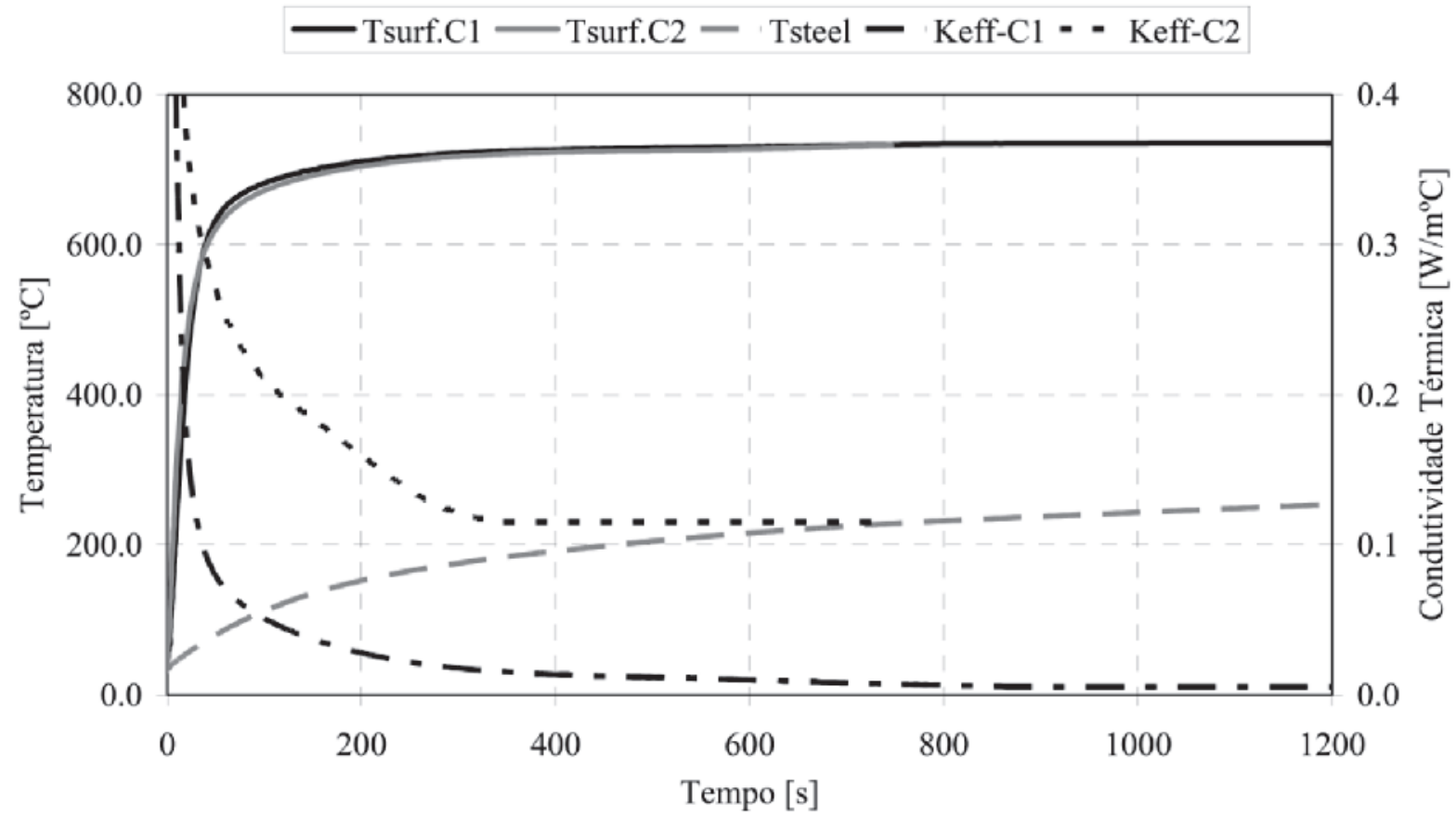

Figure 4

Thermal conductivity according to the numerical model proposed by Mesquita et al (20)

(Source: Mesquita et (20)) 
performed with a square steel plate with ten-centimeter sides, fourmillimeter thickness and painted on one side using intumescent paint with thickness of 3010 micrometers. Two hypotheses were considered: constant thickness and specific mass of the material, both equal to the initial condition of non-intumescent paint (case C1); time-dependent thickness and specific mass (case C2). Temperatures in the face of the intumescent layer and steel are also presented. It is possible to note that during the heating phase, thermal conductivity decreased until the moment where the surface temperature of the paint and steel are approximately constant. Although similar for both cases evaluated, thermal conductivity of case C2 is higher. According to Eurocode 3 apud Mesquita et al [21], temperature rise of steel profiles with fire protection, $\mathrm{nT}_{\mathrm{s}}$, can be calculated by Equation 15, as the formula proposed by Wickström.

$$
\mathrm{nT}_{\mathrm{s}}=\frac{\left(\mathrm{T}_{\mathrm{g}}-\mathrm{T}_{\mathrm{s}}\right)}{\left(\frac{\mathrm{c}_{\mathrm{s}} \rho_{\mathrm{s}}}{\mathrm{A}_{\mathrm{p}} / \mathrm{V}}\right) \cdot\left(\frac{\mathrm{d}_{\mathrm{p}}}{\mathrm{k}_{\mathrm{p}}}\right) \cdot\left(1-\frac{\varnothing}{3}\right)} \mathrm{nt}-\left(\mathrm{e}^{\varnothing / 10}-1\right) \cdot \mathrm{nT}_{\mathrm{g}}
$$

As $\varnothing=c_{p} \cdot \rho_{p} \cdot d_{p} /\left[c_{s} \cdot \rho_{s} /\left(A_{p} / V\right)\right], c_{s}$ and $\rho_{s}$ represent the specific heat and density of steel, respectively; $\mathrm{nT}_{\mathrm{g}}$ the increase in temperature occurred in the interval $n t ; T_{g}$ and $T_{s}$ temperatures in the steel environment; $A_{p} / V$ the massiveness factor (ratio between the area exposed to fire and the heated volume); $c_{p}, k_{p}$ and $\rho_{\mathrm{p}}$ the specific heat, thermal conductivity and volumetric mass of the protection, respectively, and $d_{p}$, the thickness of the protective layer.

The inversion of Equation 15 enables to obtain, directly, the thermal conductivity of the protective material and determine the variation of this property with protection temperature - according to the temperature of the environment and the metal substrate. However, it is assumed that the thickness of intumescent paint is constant and equal to the initial thickness.

$$
\mathrm{k}_{\mathrm{p}}=\left[\frac{\mathrm{c}_{\mathrm{s}} \cdot \rho_{\mathrm{s}} \cdot\left(1-\frac{\varnothing}{3}\right) \cdot \mathrm{d}_{\mathrm{p}}}{\left(\mathrm{T}_{\mathrm{g}}-\mathrm{T}_{\mathrm{s}}\right) \cdot \mathrm{nt} \cdot \mathrm{A}_{\mathrm{p}} / \mathrm{V}}\right] \cdot\left[\mathrm{nT}_{\mathrm{s}}+\left(\mathrm{e}^{\varnothing / 10}-1\right) \cdot \mathrm{nT}_{\mathrm{g}}\right] \text { (16) }
$$

Mesquita et al [21] states that intumescent paint may be considered as light protective material since, in general, for protective thickness applied to the portion $c_{p} \cdot \rho_{p} \cdot d_{p} \cdot A_{p}$, it is less than half the thermal capacity of steel. When this occurs, it may be assumed that $\varnothing=0$.

The main difference between the studies proposed by Mesquita et al [21] and Mesquita et al [20] with the others presented in this article is the focus: the metal structure. Therefore, there is no objective to accurately describe the development of physical properties during intumescence, but a sufficiently adequate approximation for achieving a qualitative approach on the temperature in the metal substrate protected. Thus, the proposed thermal conductivity is an approximation, with theoretical and normative basis, which enables the comparison with computer models of experimental tests performed, predicting the structural behavior of metallic elements.

\section{Conclusions}

Although marketed for over 40 years and with widespread use until the late 1980s, most publications on intumescent paint were derived from the patent literature, where little was displayed on the physical-chemical mechanism of intumescence. Current knowledge of the chemical composition and intumescence reactions is relatively broad and well-founded. However, although a considerable amount of chemical components that meet the characteristics required for intumescent behavior are available, only a few are used in practice and, in general, their selection is made empirically. The spread of the chemical approach has also enabled progress for the models that depict the physical properties of intumescent paint. At first, the development of intumescence was depicted through mass loss and balance. Current proposals tend to segment the process, presenting a closer path to the actual behavior of intumescence. On the other hand, keeping the focus on the substrate, it is possible to note that simplified models, though less realistic from the physical-chemical point of view, depict with relative precision the temperature rise on the protected surface.

It is latent, however, the difference on the current stage of research in Brazil related to the rest of the world. Few national publications are intended for thermal protection elements and even rarer are the studies devoted to portray a specific material as in this case, intumescent paint. Possibly, part of this little interest in the technological development of intumescent materials is due to the fact that, as a rule, it is an imported product, manufactured in other countries, and in Brazil it has applications that are still quite specific - for example used in refineries and off-shore platforms. Furthermore, there are no national standards covering testing and performance of intumescent materials or even other protective materials.

This scenario is likely to be changed in the near future. In addition to the arrival of manufacturers in the country, the recent occurrences of fires have brought to the attention of society, among others, issues on the regulation of fire protection elements. Thus, this article seeks to contextualize the different theoretical approaches on intumescent paint in the rest of the world and thus enable a start for national research in the same level as seen internationally.

\section{Acknowledgment}

I would like to thank and dedicate this article to my supervisor, prof. Dr. Armando Lopes Moreno Junior, and co-supervisor prof. Dr. Luiz Carlos Marcos Vieira Junior, for all the support and shared knowledge. Also, to the engineers Celso Vaz Santiago, Rafael Mesquita Chavez and phD Antonio Wanderley Terni. To Projectus Consultoria Ltda for the encouragement in my constant qualification. And, finally, to my family, for the affection and encouragement.

\section{References}

[1] MELHADO, S. B. Edifícios de Estruturas de Aço - Segurança Contra Incêndios e Critérios de Proteção de Estruturas. Dissertação (Mestrado em Engenharia Civil) - Escola Politécnica, Universidade de São Paulo, São Paulo, 1989.

[2] SILVA, V. P. Estruturas de Aço em Situação de Incêndio. 1997. Tese (Doutorado em Engenharia Civil) - Escola Politécnica, Universidade de São Paulo, São Paulo, 1997.

[3] ABREU, L. M. P.; FAKURY, R. H. Elevação de Temperatura 
em Elementos Estruturais de Aço de Edifícios em Incêndio. In: VII SEMANA DE INICIAÇÃO CIENTÍFICA DA UFMG, Minas Gerais, 1998

[4] FAKURY, R. H. Dimensionamento de estruturas de aço de edifícios em situação de incêndio. In: SEMINÁRIO INTERNACIONAL "O USO DE ESTRUTURAS METÁLICAS NA CONSTRUÇÃO CIVIL”, 2., Belo Horizonte: SME, 1999.

[5] MARTINS, M. M. Dimensionamento de Estruturas de Aço em Situação de Incêndio. 2000. 213 f. Dissertação (Mestrado em Engenharia Civil) - Escola de Engenharia, Universidade Federal de Minas Gerais, Minas Gerais, 2000.

[6] LOPES RIBEIRO, J. C., Simulação via método dos elementos finitos da distribuição tridimensinal de temperatura em estruturas em situação de incêndio. Dissertação (Mestrado em Engenharia de Estruturas) - Escola de Engenharia, Universidade Federal de Minas Gerais, Minas Gerais 2004.

[7] GUIMARÃES, P. P. O. Sobre o Dimensionamento do Revestimento Contra Fogo em Estruturas de Aço. 2007. 265 f. Dissertação (Mestrado em Engenharia Civil) - Escola Politécnica, Universidade de São Paulo, São Paulo, 2007.

[8] Andrade, C. C. Proteção térmica em elementos estruturais de aço. Dissertação (Mestrado em Arquitetura e Urbanismo) - Universidade Federal de Santa Catarina. - Florianópolis, SC, 2010.

[9] TROITZSCH, J. H. Methods for the Fire Protection of Plastics and Coatings by Flame Retardant and Intumescent Systems.Marl, 1983.

[10] CAMINO, G., COSTA. L., MARTINASSO, G. Intumescent Fire-Retardant Systems. Torino, 1988.

[11] NØRGAARD, K. P., DAM-JOHANSEN, K., CATALÀ, P. KIIL, S. Laboratory and Gas-Fired Furnace Performance Tests of Epoxy Primers for Intumescent Coatings.Lyngby, 2014.

[12] JIMENEZ, M, DUQUESNE, S., BOURBIGOT, S. Characterization of the Performance of an Intumescent Fire Protective Coating. Villeneuve d'Ascq, 2006.

[13] RESHETNIKOV, I. S., GARASHCHENKO, A. N., STRAKHOV, V. L. Experimental investigation into mechanical destruction of intumescent chars. 2000.

[14] NøRGAARD, K. P., DAM-JOHANSEN, K., CATALÀ, P. KIIL, $S$. Investigation of Char Strength and Expansion Properties of an Intumescent Coating Exposed to Rapid Heating Rates. Lyngby, 2013.

[15] CLARK, K. J., SHIMIZU, A. B., SUCHSLAND, K. E., MOYER, C. B. Aerotherm Final Report 74-101 - Analytical Modeling of Intumescent Coating Thermal Protection System in a JP-5 Fuel Fire Environment. Califórnia, 1974.

[16] ANDERSON, C. E., WAUTERS, K. D.A Thermodynamic Heat Transfer Model for Intumescent Systems.San Antonio, 1984.

[17] BUCKMASTER, J., ANDERSON, C., NACHMAN, A. A Model for Intumescent Paints. Ilinóis/San Antonio, 1986.

[18] DEOGON, M., HALL, R., SOCRATES, G. A Simple Theoretical Model for Intumescent Paints. Londres, 1988.

[19] STAGGS, J. E. J. Thermal Conductivity Estimates of Intumescent Chars by Direct Numerical Simulation. Leeds, 2010

[20] MESQUITA, L. M. R.; PILOTO, P. A. G.; VAZ, M. A. P., PINTO, T. Determinação da Condutividade Térmica Efectiva de
Tintas Intumescentes. In: $7^{\circ}$ CONGRESSO NACIONAL DE MECÂNICA EXPERIMENTAL, Vila Real, 2008.

[21] MESQUITA, L. M. R.; PILOTO, P. A. G.; VAZ, M. A. P.; VILA REAL, P. M. M.; RAMOS, F. Comportamento de Vigas em Aço Protegidas com Tinta Intumescente. In: V CONGRESSO DE CONSTRUÇÃO METÁLICA E MISTA, Lisboa, 2005.

[22] AMERICAN SOCIETY FOR TESTING AND MATERIALS. ASTM E-736 Standard Test Method for Cohesion/Adhesion of Sprayed Fire-Resistive Materials Applied to Structural Members. Filadélfia, 2011.

[23] AMERICAN INSTITUTE OF STEEL CONSTRUCTION. AISC Desing Guide 19 Fire Resistance of Structural Steel Framing. Chicago, 2003.

[24] ASSOCIAÇÃO BRASILEIRA DE NORMAS TÉCNICAS. NBR 8800: Projeto de estruturas de aço e de estruturas mistas de aço e concreto de edifícios. Rio de Janeiro, 2008.

[25] ASSOCIAÇÃO BRASILEIRA DE NORMAS TÉCNICAS. NBR 8681: Ações e segurança nas estruturas - Procedimento. Rio de Janeiro, 2004.

[26] ASSOCIAÇÃO BRASILEIRA DE NORMAS TÉCNICAS. NBR 14323: Projeto de estruturas de aço e de estruturas mistas de aço e concreto de edifícios em situação de incêndio. Rio de Janeiro, 2013.

[27] ASSOCIAÇÃO BRASILEIRA DE NORMAS TÉCNICAS. NBR 14432: Exigências de resistência ao fogo de elementos construtivos de edificações - Procedimento. Rio de Janeiro, 2000.

[28] BERTELLI, G., CAMINO, G., MARCHETTI, E., COSTA. L., CASORATI, E., LOCATELLI, R. Parameters Affecting Fire Retardant Effectiveness in Intumescent Systems. Torino, 1988.

[29] CHEN, C. K, ZENG, J. W., SHEN, B. Y. Experimental Investigation on Fire Response of Steel Plate with Ultrathin Intumescent Coatings. Changsha, 2013.

[30] COMITE EUROPEU DE NORMALIZAÇÃO. Eurocode1: Acções em estruturas. Bruxelas, 2009

[31] COMITE EUROPEU DE NORMALIZAÇÃO. Eurocode2Projecto de estruturas de betão. Bruxelas, 2007.

[32] COMITE EUROPEU DE NORMALIZAÇÃO. Eurocode3Projecto de estruturas de aço. Bruxelas, 2010.

[33] CORTEZ, I. M. M. Contribuição ao Estudo dos Sistemas de Revestimento à Base de Argamassa com Incorporação de Fibras Sintéticas. Dissertação (Mestrado em Engenharia Civil) - Faculdade de Tecnologia, Universidade de Brasília, Brasília, 1999.

[34] DAI, X. H., WANG, Y. C., BAILEY, C. G...Effects of Partial Fire Protection on Temperature Developments in Steel Joints Protected by Intumescent Coating.Manchester, 2008.

[35] DRYSDALE, D.An Introduction to Fire Dynamics. 2nd ed. Chichester, U.K.: John Wiley \& Sons, 2000. 451p.

[36] EUROPEAN ORGANIZATION FOR TECHNICAL APPROVALS.ETAG No 018 - Guideline for European Technical Approval of Fire Protective Products.Bruxelas, 2011.

[37] GERARD, C., FONTAINE, G., BELLAYER, S., BOURBIGOT, S. Reaction to Fire of an Intumescent Epoxy Resin: Protection Mechanisms and Synergy. Lille, 2012.

[38] GOMES-MARES, M., TUGNOLI, A., LANDUCCI, G., BARONTINI, F., COZZANI, V. Behavior of Intumescent Epoxy 
Resins in Fireproofing Applications.Pisa, 2012.

[39] JIMENEZ, M, DUQUESNE, S., BOURBIGOT, S. Intumescent Fire Protective Coating: Toward a Better Understanding of Their Mechanism of Action. Villeneuve d'Ascq, 2006.

[40] LIANG, H., SHI, W., GONG, M. Expansion Behavior and Thermal Degradation of Tri(acryloyloxyethyl) Phosphate/ Methacrylated Phenolic Melamine Intumescent Flame Retardant System. Hefei, 2005.

[41] MEHTA, P. K.; MONTEIRO, P. J. M. Concreto: Estrutura, Propriedades e Materiais. PINI, São Paulo, 1994.

[42] MESQUITA, L. M. R.; PILOTO, P. A. G.; VAZ, M. A. P. Caracterização do Comportamento e das Propriedades Termofísicas de Tintas Intumescentes. In: CONGRESSO DE CONSTRUÇÃO METÁLICA E MISTA, Lisboa, 2006.

[43] PANNONI, F. D. Coletânea do Uso de Aço: Princípios da Proteção de Estrutura Metálicas em Situação de Corrosão e Incêndio, $4^{\mathrm{a}}$ edição. Perfis Gerdau Açominas. 2007

[44] PEREIRA, A. A. Estudo Experimental e Simulação Numérica do Comportamento de Tintas Intumescentes na Protecção de Elementos Estruturais em Condição de Incêndio. Bragança, 2009.

[45] SILVA, V. P. Estruturas de Aço em Situação de Incêndio. ZigurateEditora, São Paulo, 2001. 249p.

[46] STAGGS, J. E. J., CREWE, R. J., BUTLER, R.A Theoretical and Experimental Investigation of Intumecent Behavior in Protective Coatings for Structual Steel.Leeds, 2011.

[47] VEIGA, M. R. S.; ABRANTES, V. Improving the Cracking Resistance of Rendering Mortars - Influence of Composition Factors. In: XXV IAHS World Housing Congress, Lisboa, 1998.

[48] ZHANG, Y., WANG, .Y C., BAILEY, C. G., TAYLOR, A. P. Global Modelling of Fire Protection Performance of Intumescent Coating Under Different Cone Calorimeter Heating Conditions. Bolton, 2012. 